\title{
Effects of perpetrator identity on suicidality and nonsuicidal self-injury in sexually victimized female adolescents
}

This article was published in the following Dove Press journal:

Neuropsychiatric Disease and Treatment

21 June 2016

Number of times this article has been viewed

\section{Gulsen Unlu \\ Burcu Cakaloz \\ Department of Child and Adolescent Psychiatry, Faculty of Medicine, Pamukkale University, Denizli, Turkey}

Purpose: Child sexual abuse and sexual dating violence victimization are common problems that are known to have long-term negative consequences. This study aimed to compare the sociodemographic, abuse-related, and clinical features of female adolescents who were sexually abused by different perpetrators, and identify the factors associated with suicidality and nonsuicidal self-injury (NSSI) in these cases.

Patients and methods: Data of 254 sexually abused female adolescents between the ages of 12-18 years were evaluated. The cases were classified into three groups, namely "sexual dating violence", "incest", and "other child sexual abuse", according to the identity of the perpetrator. The three groups were compared in terms of sociodemographic, abuse-related, and clinical features.

Results: Major depressive disorder was the most common psychiatric diagnosis, which was present in $44.9 \%$ of the cases. Among all victims, $25.6 \%$ had attempted suicide, $52.0 \%$ had suicidal ideation, and $23.6 \%$ had NSSI during the postabuse period. A logistic regression analysis revealed that attempted suicide was predicted by dating violence victimization (adjusted odds ratio $[\mathrm{AOR}]=3.053 ; 95 \%$ confidence interval $[\mathrm{CI}]=1.473,6.330)$ and depression $(\mathrm{AOR}=2.238$; $95 \% \mathrm{CI}=1.226,4.086)$. Dating violence victimization was also the strongest predictor of subsequent suicidal ideation ( $\mathrm{AOR}=3.500 ; 95 \% \mathrm{CI}=1.817,6.741$ ). In addition, revictimization was determined to be an important risk factor for both suicidal ideation $(\mathrm{AOR}=2.897 ; 95 \% \mathrm{CI}=1.276$, 6.574) and NSSI (AOR $=3.847$; 95\% CI $=1.899,7.794$ ).

Conclusion: Perpetrator identity and revictimization are associated with negative mental health outcomes in sexually victimized female adolescents. Increased risk of suicidality and NSSI should be borne in mind while assessing cases with dating violence and revictimization histories, in particular.

Keywords: sexual abuse, dating violence, incest, mental health, suicide, self-harm

\section{Introduction}

Sexual abuse can be defined as all kinds of sexual acts where consent is not, or cannot be, given. Those sexual acts that take place by the use of force or threat, regardless of the age of the participants, and all kinds of sexual acts that take place between a child and an adult, regardless of whether the child is able to perceive the sexual nature of the act, are sexual abuse. Sexual contact between a teenager and a younger child can also be abusive if there is a significant incongruity in age, development, or size. ${ }^{1}$

A meta-analysis research exhibited an estimated prevalence of child sexual abuse (CSA) of $8 \%-31 \%$ for girls and $3 \%-17 \%$ for boys. ${ }^{2}$ Although sexual abuse is reported to
Correspondence: Gulsen Unlu Department of Child and Adolescent Psychiatry, Faculty of Medicine, Pamukkale University, University Street, 20070, Kinikli, Denizli, Turkey Tel +90258296 6000 ext 45I9 $\mathrm{Fax}+902582966001$

Email gulsenu@pau.edu.tr 
be more frequent in girls, some researchers argue that it may be associated with the difficulty in noticing sexual abuse in boys and with the lower rate of its disclosure. ${ }^{3,4}$ School-based studies carried out in Turkey with adolescents and young adults estimated CSA prevalence to be $10.7 \%-28.0 \% 0^{5,6}$ and incest prevalence to be $1.8 \%-4.4 \%$. 5,7

Teen dating violence is defined as abuse, harassment, or stalking of an adolescent between 12 years and 18 years of age in the context of a past or present romantic or consensual relationship. ${ }^{8}$ Dating violence may occur in the form of psychological or emotional violence, physical violence, and sexual violence. ${ }^{9}$ Studies demonstrate that approximately one in five female adolescents suffer physical and/or sexual violence by her partner during a dating relationship, ${ }^{10}$ and that the older the age is, the higher the risk becomes. ${ }^{11}$ Both dating violence victimization and CSA are associated with adverse mental health outcomes such as depression, ${ }^{11-13}$ posttraumatic stress disorder (PTSD), ${ }^{12-15}$ alcohol/substance use disorders, ${ }^{10,11,15}$ nonsuicidal self-injury (NSSI), ${ }^{9,14}$ and suicidality. ${ }^{10,13,14}$

Although the negative effects of teen dating violence are widely known, the subject has remained under-researched in non-Western countries. Despite the multitude of studies ${ }^{5-7}$ conducted in Turkey to address CSA and domestic violence sustained by married or pregnant women, there is no research in the literature, to the best of our knowledge, about sexual dating violence in adolescents.

The aim of this study was to compare the sociodemographic, abuse-related, and clinical features of female adolescents who were sexually abused by different perpetrators and to identify the factors associated with suicidality and NSSI.

\section{Patients and methods}

Mental or physical deterioration incurred by the child as a result of sexual abuse was referred to as an aggravating circumstance under the Turkish Penal Code, which remained in force from 2005 to $2014 .{ }^{16}$ Until the year 2014 when the law was amended, expert opinion had been called for to evaluate whether the sexually abused child and adolescent incurred any deterioration in their mental or physical health.

The study took place in Denizli, located in Western Turkey, which has mixed sociocultural characteristics due to internal migration. Victims of sexual abuse in the city of Denizli and its vicinity are usually referred to our university hospital for forensic evaluation. All cases referred to the Department of Child and Adolescent Psychiatry at Pamukkale University Faculty of Medicine for the purpose of forensic psychiatric evaluation are subjected to a standard assessment. All the data are entered into a "Sexual Abuse Data Form" designed by researchers, and such a form is archived at the Department together with the inquiry documents forwarded by the penal authority and a copy of the expert's report. The Sexual Abuse Data Form is a standard data form where sociodemographic data related to the cases and their families as well as detailed information on the sexual abusive episode, postabuse psychiatric symptoms, findings from the psychiatric examination, and the psychiatric diagnosis made based on the Diagnostic and Statistical Manual of Mental Disorders, fourth edition, text revision diagnostic criteria ${ }^{17}$ are recorded. The data form also includes information about the perpetrator (number of perpetrators and the proximity of each perpetrator to the victim) derived from the victim and the inquiry documents forwarded by the penal authority.

The study involved a retrospective evaluation of the data of 254 sexually victimized female adolescents from 12 years to 18 years of age who were assessed during a period of 6 years from January 2008, when the Sexual Abuse Data Form was introduced into routine use, to December 2013. They were assessed after at least 6 months following the abusive episode or followed up for 6 months after the episode. The cases were classified into three groups, namely "sexual dating violence", "incest", and "other CSA", according to the identity of the perpetrator. Those adolescents who were abused by a person with whom they had a past or present romantic or consensual relationship constituted the "sexual dating violence" group, ${ }^{8}$ those who were abused by their close blood relatives (eg, father/mother, uncle/aunt, and sibling), stepparents, or stepsiblings formed the incest group, ${ }^{18}$ and those who were abused by other persons (eg, acquaintances and strangers) made up the "other CSA" group. Cases that could be included in more than one group (eg, victims of both incest and sexual dating violence) were excluded from the study. The three groups were compared with respect to sociodemographic features, characteristics of the abusive act, psychiatric disorders, suicidality (attempted suicide and suicidal ideation), and NSSI. Being abused by different perpetrators, who unconnected with each other, was defined as "revictimization". Being exposed to repetitive abuse by the same perpetrator was defined as "chronic abuse".

This study was approved by the Medical Ethics Committee of the Pamukkale University Faculty of Medicine. Due to retrospective nature of the study, written informed consent was not necessary, as stated by the committee.

\section{Statistical analyses}

All analyses were conducted using the SPSS (Version 15.0) (IBM Corporation, Armonk, NY, USA) for Windows. 
A Kruskal-Wallis test or a chi-square test was used in between-group comparisons. In the event of a statistical difference found among the three groups, post hoc analysis was performed to determine from which groups the difference resulted. The $P$-values from the three pairwise comparisons for each continuous variable were evaluated using a Bonferroni correction to maintain the overall Type I error rate of 0.05 , yielding an alpha of $0.05 / 3=0.016$ as the threshold for significance. The statistical significance level was set at 0.05 for all other analyses. Logistic regression analysis was performed in order to identify the factors associated with attempted suicide, suicidal ideation, and NSSI. Separate logistic regression models were constructed to identify sociodemographic, abuse-related, and clinical variables that were significantly associated with the dependent variables. All significant factors were included in the final multivariable logistic regression models for each of these three dependent variables.

\section{Results}

\section{Characteristics of the victims}

One hundred and twenty-five (49.2\%) girls were referred for sexual dating violence, 33 (13.0\%) girls for incest, and $96(37.8 \%)$ girls for sexual abuse by other persons. Table 1 illustrates the sociodemographic features of cases. The mean age of all the victims was $15.2 \pm 1.5$ years at the stage of referral. The mean age of sexual dating violence victims was higher than that of the other CSA victims $(P=0.006)$. Approximately half of the victims were not attending school at the stage of assessment. Forty-nine (19.3\%) of the cases had dropped out before the abuse and $71(28.0 \%)$ after the abuse. The dropping out rate after the abuse was higher in the sexual dating violence group than the other CSA group $(P=0.001)$. The majority of the victims $(77.6 \%)$ were living together with their parents. Living in institutional care was higher in the incest group than both the sexual dating violence and the other CSA groups $(P=0.002$ and $P<0.001$, respectively).

The victims in the incest group had younger parents compared with those in the other two groups, although a statistically significant difference was detected only in the father's age. Fathers of incest cases were younger than fathers of sexual dating violence victims $(P=0.013)$. Low socioeconomic status was more common in the incest group than in the sexual dating violence group $(P=0.008)$. The number of children in a family was higher in the incest group than in the sexual dating violence group $(P=0.011)$. The percentage

Table I Sociodemographic features of sexual dating violence, incest, and other CSA victims

\begin{tabular}{|c|c|c|c|c|c|}
\hline Characteristics & Dating violence $(n=\mid 25)$ & Incest $(n=33)$ & Other CSA $(n=96)$ & Total $(\mathrm{N}=254)$ & $P$-value \\
\hline Age, mean $\pm S D$ (range), years & $15.5 \pm 1.3(12-18)$ & $15.2 \pm 1.4(13-18)$ & $14.9 \pm 1.6(12-18)$ & $15.2 \pm 1.5(12-18)$ & 0.019 \\
\hline Dropout from school before abuse, $n$ (\%) & & & & & 0.611 \\
\hline Yes & $25(20.0)$ & $8(24.2)$ & $16(16.7)$ & $49(19.3)$ & \\
\hline No & $100(80.0)$ & $25(75.8)$ & $80(83.3)$ & $205(80.7)$ & \\
\hline Dropout from school after abuse, $n$ (\%) & & & & & 0.002 \\
\hline Yes & $47(37.6)$ & $8(24.2)$ & $16(16.7)$ & $71(28.0)$ & \\
\hline No & $78(62.4)$ & $25(75.8)$ & $80(83.3)$ & $183(72.0)$ & \\
\hline Living with, $\mathrm{n}(\%)$ & & & & & $<0.001$ \\
\hline Parent(s) & $95(76.0)$ & $18(54.5)$ & $84(87.5)$ & $197(77.6)$ & \\
\hline Relatives & $7(5.6)$ & $2(6.1)$ & $3(3.1)$ & $12(4.7)$ & \\
\hline Partner & $8(6.4)$ & I (3.0) & $2(2.1)$ & II (4.3) & \\
\hline In an institution & $15(12.0)$ & $12(36.4)$ & $6(6.2)$ & $33(13.0)$ & \\
\hline No data & - & - & $I(1.0)$ & $\mathrm{I}(0.4)$ & \\
\hline Father's age, mean \pm SD (range), years & $44.2 \pm 6.3(33-65)$ & $41.3 \pm 8.3(30-73)$ & $44.4 \pm 7.4(30-78)$ & $43.9 \pm 7.0(30-78)$ & 0.036 \\
\hline Mother's age, mean \pm SD (range), years & $40.4 \pm 6.3(31-60)$ & $38.0 \pm 7.4(28-63)$ & $39.3 \pm 6.5(29-59)$ & $39.7 \pm 6.6(28-63)$ & 0.070 \\
\hline Number of children, mean \pm SD (range) & $2.6 \pm 1.2(1-7)$ & $3.3 \pm 1.6(I-9)$ & $2.7 \pm 1.2(I-8)$ & $2.8 \pm 1.3(I-9)$ & 0.040 \\
\hline Marital status, n (\%) & & & & & 0.005 \\
\hline Married/cohabiting & $85(68.8)$ & $13(39.4)$ & $62(64.6)$ & $160(63.0)$ & \\
\hline Divorced/separated & $26(20.8)$ & $18(54.5)$ & $26(27.1)$ & $70(27.6)$ & \\
\hline Widowed & $12(9.6)$ & $2(6.1)$ & $6(6.2)$ & $20(7.9)$ & \\
\hline No data & $2(1.6)$ & - & $2(2.1)$ & $4(1.6)$ & \\
\hline Household income, $n(\%)$ & & & & & 0.018 \\
\hline Not regular/low & $29(23.2)$ & $17(5 \mid .5)$ & $29(30.2)$ & $75(29.5)$ & \\
\hline Middle/high & 81 (64.8) & $15(45.5)$ & $58(60.4)$ & I54 (60.6) & \\
\hline No data & $15(12.0)$ & I (3.0) & $9(9.4)$ & $25(9.8)$ & \\
\hline
\end{tabular}

Note: $P$-values were obtained by the Kruskal-Wallis test or the $\chi^{2}$ test.

Abbreviations: CSA, child sexual abuse; SD, standard deviation. 
of broken family was also higher in the incest group than in the other two groups $(P=0.005)$.

\section{Characteristics of sexual abuse}

All perpetrators were male. Table 2 illustrates the findings regarding the sexual abuse in the cases. The mean age of all the victims at first abusive episode was 14.0 \pm 1.9 (7-17.5) years. Age at the first abusive episode in the three groups showed a statistically significant difference $(P<0.001)$. The incest group was the one abused at the youngest age, whereas the sexual dating violence group suffered abuse at the oldest age. The length of time that elapsed from the first abusive episode until the assessment was $21.6 \pm 1.7$ (6-96) months on average and longer in the incest group than in the other two groups $(P<0.001)$.

The percentage of the chronic abuse by the same perpetrator was different among the three groups. The rate was highest in the incest group and lowest in the other CSA group $(P<0.001)$. Approximately one-quarter of the victims were abused by more than one perpetrator, and the rate was higher in the sexual dating violence group compared with the other CSA group $(P=0.002)$. Revictimization was also more common in the sexual dating violence group than in the other CSA group $(P=0.003)$.

Among all victims, 164 (64.6\%) were subjected to vaginal or anal penetration. The rate of penetration was higher in the sexual dating violence group when compared with the other two groups $(P<0.001)$. Approximately one-quarter of the victims were additionally subjected to physical assault during the abuse. The percentage of victims suffering from physical violence was higher in the incest and sexual dating violence groups than in the other CSA group $(P=0.002)$.
More than half of the victims were threatened by the perpetrator during or after the abusive episode. The rate of the perpetrator's use of threats was higher in the sexual dating violence group than in the other CSA group $(P=0.012)$. The rate of the victim's confinement by the perpetrator was not assessed for the incest group, and there was no discrepancy between the sexual dating violence and other CSA groups in that respect $(P=0.219)$. Pregnancy resulted from rape was reported by $34(13.4 \%)$ of the victims, and the prevalence of pregnancy was not different among the groups. Outcome of the pregnancy remained unknown in nine of the 34 cases $(26.5 \%)$ as they dropped out from the follow-up process. Eleven $(32.4 \%)$ cases underwent termination of pregnancy, whereas in $14(41.2 \%)$ victims the pregnancy ended with delivery.

\section{Results of psychiatric assessment}

At least one abuse-related psychiatric disorder was determined in $230(90.6 \%)$ of the victims (Table 3). It was found that $47(18.5 \%)$ of the cases developed more than one psychiatric disorder. The most common psychiatric diagnosis was major depressive disorder, which was present in $114(44.9 \%)$ of the cases, followed by PTSD in $91(35.8 \%)$ and adjustment disorder in $28(11.0 \%)$ of the cases. Percentages of both those with any diagnosed psychiatric disorders and those with diagnosed depressive disorders were higher in the sexual dating violence group than in the other CSA group $(P=0.007$ and $P=0.009$, respectively).

Among all victims, 65 (25.6\%) had attempted suicide after the abuse, $132(52.0 \%)$ had suicidal ideation, and 60 $(23.6 \%)$ had NSSI. Attempted suicide and suicidal ideation

Table 2 Abuse-related characteristics of sexual dating violence, incest, and other CSA victims

\begin{tabular}{|c|c|c|c|c|c|}
\hline Characteristics & Dating violence $(n=\mid 25)$ & Incest $(n=33)$ & Other CSA $(n=96)$ & Total $(\mathrm{N}=254)$ & $P$-value \\
\hline $\begin{array}{l}\text { Age at first abusive episode, mean } \pm S D \\
\text { (range), years }\end{array}$ & $14.6 \pm 1.4(9.5-17.5)$ & $12.3 \pm 2.4(7.0-16.0)$ & $13.8 \pm 1.9(8.0-17.5)$ & $14.0 \pm 1.9(7.0-17.5)$ & $<0.001$ \\
\hline $\begin{array}{l}\text { Length of time since the (first) trauma } \\
\text { (months), mean } \pm \mathrm{SD} \text { (range) }\end{array}$ & $17.3 \pm 1.2(6-84)$ & $42.7 \pm 2.5(8-96)$ & $20.0 \pm 1.5(6-72)$ & $21.6 \pm 1.7(6-96)$ & $<0.001$ \\
\hline More than one offender, $\mathrm{n}(\%)$ & $4 \mathrm{I}(32.8)$ & $7(2 \mid .2)$ & $13(13.5)$ & $61(24.0)$ & 0.004 \\
\hline Number of offenders, mean \pm SD (range) & $1.66 \pm 1.55(1-14)$ & $I .2 I \pm 0.4 I(I-2)$ & $1.49 \pm 1.80(1-13)$ & $1.54 \pm 1.56(1-14)$ & 0.003 \\
\hline Chronic abuse by the same offender, $\mathrm{n}(\%)$ & $68(54.4)$ & $28(84.8)$ & $37(38.5)$ & $133(52.4)$ & $<0.001$ \\
\hline Revictimization, n (\%) & $34(27.2)$ & $6(18.2)$ & $10(10.4)$ & $50(19.7)$ & 0.008 \\
\hline Penetration, n (\%) & $109(87.2)$ & $17(5 \mid .5)$ & $38(39.6)$ & $164(64.6)$ & $<0.001$ \\
\hline Physical assault, n (\%) & $32(25.6)$ & 14 (42.4) & $13(13.5)$ & $59(23.2)$ & 0.002 \\
\hline Threat, n (\%) & $72(57.6)$ & $19(57.6)$ & $39(40.6)$ & $130(5 \mid .2)$ & 0.032 \\
\hline Confinement, n (\%) & $29(23.2)$ & NA & $15(15.6)$ & $44(19.9)$ & 0.219 \\
\hline Pregnancy, n (\%) & $21(16.8)$ & $3(9.1)$ & $10(10.4)$ & $34(13.4)$ & 0.285 \\
\hline
\end{tabular}

Note: $P$-values were obtained by the Kruskal-Wallis test or the $\chi^{2}$ test.

Abbreviations: CSA, child sexual abuse; SD, standard deviation; NA, not applicable. 
Table 3 Negative mental health consequences of different types of sexual abuse

\begin{tabular}{|c|c|c|c|c|c|}
\hline Mental health consequences & $\begin{array}{l}\text { Dating violence } \\
(n=125)\end{array}$ & $\begin{array}{l}\text { Incest } \\
(n=33)\end{array}$ & $\begin{array}{l}\text { Other CSA } \\
(n=96)\end{array}$ & $\begin{array}{l}\text { Total } \\
(\mathbf{N}=254)\end{array}$ & $P$-value \\
\hline Any psychiatric disorder, ${ }^{\mathrm{a}} \mathrm{n}(\%)$ & $119(95.2)$ & $30(90.9)$ & $80(83.3)$ & $229(90.2)$ & 0.013 \\
\hline Number of psychiatric disorders, mean \pm SD (range) & $1.15 \pm 0.50(0-3)$ & $1.12 \pm 0.59(0-3)$ & $1.05 \pm 0.63(0-3)$ & $1.1 \mathrm{I} \pm 0.57(0-3)$ & 0.395 \\
\hline Major depressive disorder, $\mathrm{n}(\%)$ & $65(52.0)$ & $16(48.5)$ & $33(34.4)$ & II 4 (44.9) & 0.030 \\
\hline Posttraumatic stress disorder, n (\%) & $39(31.2)$ & $10(30.3)$ & $42(43.8)$ & $91(35.8)$ & 0.121 \\
\hline Adjustment disorders, n (\%) & $18(14.4)$ & $2(6.1)$ & $8(8.3)$ & $28(11.0)$ & 0.224 \\
\hline Other psychiatric disorders, ${ }^{b} \mathrm{n}(\%)$ & $14(\mid 1.2)$ & $4(12.1)$ & II (II.5) & $29(11.4)$ & 0.989 \\
\hline Attempted suicide, n (\%) & $44(35.2)$ & $9(27.3)$ & $12(12.5)$ & $65(25.6)$ & $<0.001$ \\
\hline Suicidal ideation, n (\%) & $85(68.0)$ & $17(5 \mid .5)$ & $30(31.2)$ & $132(52.0)$ & $<0.001$ \\
\hline Nonsuicidal self-injury, n (\%) & $34(27.2)$ & $8(24.2)$ & $18(18.8)$ & $60(23.6)$ & 0.340 \\
\hline
\end{tabular}

Notes: $P$-values were obtained by the Kruskal-Wallis test or the $\chi^{2}$ test. ${ }^{a}$ Forty-seven of victims had more than one psychiatric disorders. ${ }^{b} O$ ther psychiatric disorders include alcohol/substance use disorders $(n=13,5.1 \%)$, conversion disorder $(n=10,3.9 \%)$, conduct disorder $(n=4,1.5 \%)$, borderline personality traits $(n=3$, $1.1 \%)$, body dysmorphic disorder $(n=I, 0.3 \%)$, and dissociative disorders $(n=I, 0.3 \%)$.

Abbreviations: CSA, child sexual abuse; SD, standard deviation.

were more common in the sexual dating violence victims than in the other CSA victims $(P<0.001)$. Results of the logistic regression analyses are provided in Table 4 . In the final model, being a dating violence victim and major depressive disorder were associated with significantly greater risk of attempted suicide. Increased likelihood of suicidal ideation was significantly associated with being a dating violence victim, revictimization, number of psychiatric diagnoses, and major depressive disorder. Revictimization and alcohol/ substance use disorders were independently associated with NSSI in the fully adjusted logistic regression model.

\section{Discussion}

The aim of the current study was to compare the sociodemographic and clinical features of female adolescents who were victims of sexual dating violence, incest, and sexual abuse by other persons and to identify factors associated with suicidality and NSSI in these cases, in particular. Our results exhibited that the sociodemographic features of the victims who suffered various types of abuse and the characteristics of the sexually abusive act committed were different from each other. Furthermore, sexual dating violence victimization was found out to be the factor that increased the likelihood of

Table 4 Factors associated with attempted suicide, suicidal ideation, and nonsuicidal self-injury in sexually victimized female adolescents

\begin{tabular}{|c|c|c|c|c|c|c|}
\hline \multirow[t]{3}{*}{ Independent variable } & \multicolumn{6}{|c|}{ Dependent variable } \\
\hline & \multicolumn{3}{|c|}{ Unadjusted } & \multicolumn{3}{|c|}{ Adjusted } \\
\hline & OR & $95 \% \mathrm{Cl}$ & $P$-value & OR & $95 \% \mathrm{Cl}$ & $P$-value \\
\hline \multicolumn{7}{|l|}{ Attempted suicide ${ }^{a}$} \\
\hline \multicolumn{7}{|l|}{ Group } \\
\hline Dating violence & 3.802 & I.874-7.7|5 & $<0.001$ & 3.053 & $1.473-6.330$ & 0.003 \\
\hline Incest & 2.625 & $0.989-6.967$ & 0.053 & 2.251 & $0.827-6.127$ & 0.112 \\
\hline Other CSA & 1.00 & - & - & 1.00 & - & - \\
\hline Depression & 2.486 & $1.394-4.436$ & 0.002 & 2.238 & $1.226-4.086$ & 0.009 \\
\hline \multicolumn{7}{|l|}{ Suicidal ideation ${ }^{\mathrm{b}}$} \\
\hline \multicolumn{7}{|l|}{ Group } \\
\hline Dating violence & 4.675 & $2.638-8.285$ & $<0.001$ & 3.500 & $|.8| 7-6.74 \mid$ & $<0.001$ \\
\hline Incest & 2.337 & I.042-5.242 & 0.039 & 1.860 & $0.737-4.696$ & 0.189 \\
\hline Other CSA & 1.00 & - & - & 1.00 & - & - \\
\hline Revictimization & 3.706 & $|.83|-7.500$ & $<0.00 \mathrm{I}$ & 2.897 & $1.276-6.574$ & 0.011 \\
\hline Depression & 4.612 & $2.70 \mathrm{I}-7.877$ & $<0.001$ & 3.208 & $1.702-6.047$ & $<0.001$ \\
\hline Number of psychiatric disorders & 3.984 & $2.239-7.087$ & $<0.001$ & 2.459 & $1.243-4.864$ & 0.010 \\
\hline \multicolumn{7}{|l|}{ Nonsuicidal self-injuryc } \\
\hline Revictimization & 4.829 & $2.488-9.372$ & $<0.001$ & 3.847 & I.899-7.794 & $<0.001$ \\
\hline Alcohol/substance use & 9.500 & $2.859-31.562$ & $<0.001$ & 5.894 & $1.654-21.002$ & 0.006 \\
\hline
\end{tabular}

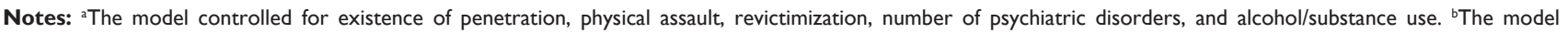
controlled for age, existence of penetration, physical assault, threat, and living with/apart from parent(s). ${ }^{c}$ The model controlled for existence of penetration, number of perpetrators, and number of psychiatric disorders.

Abbreviations: $\mathrm{OR}$, odds ratio; $\mathrm{Cl}$, confidence interval; $\mathrm{CSA}$, child sexual abuse. 
suicidality the most, whereas revictimization was associated with the likelihood of both suicidal ideation and NSSI.

The large number of sexual dating violence victims in the current study is remarkable. The results of the WHO Multi-Country Study on Women's Health and Domestic Violence showed that the most reported perpetrator who abused women $<15$ years of age was a person from her family, but the perpetrator identity differed according to countries. ${ }^{19}$ A study evaluating the reported CSA incidence in Switzerland indicated that approximately one-quarter of the victims were abused by adult males with whom they lived together, and that the perpetrators were peers (such as friends, colleagues, or neighbors) in approximately one-quarter of the cases. ${ }^{20}$ In the current study, the number of victims who were abused by their boyfriends or former boyfriends was approximately four times higher than the number of incest cases. This finding may result from the fact that our case group consisted of female adolescents among whom the likelihood of sexual dating violence is higher or may be associated with incest cases being reported less. When the perpetrator is somebody from the family, not only does it become more difficult for the victim to disclose the abuse ${ }^{21}$ but also caregivers may force the victim into withdrawing or altering the disclosure. ${ }^{22}$

This study revealed that the three groups differed from each other in terms of sociodemographic features. The victims constituting the sexual dating violence group were older and more than half of them were not attending school. Incest victims, however, differed from the others with respect to family characteristics. The findings with regard to these cases that fathers were younger, that the socioeconomic levels of families were lower, and that the percentage of broken families and the number of children in a family were higher, agreed with those of the literature. ${ }^{23,24}$ Chan et $\mathrm{al}^{25}$ reported that having siblings increased the risk of child abuse and argued that the dispersion of parental resources among children may make the child more vulnerable to abuse. Disclosure of incest may have contributed to the high percentages of divorce particularly in the events where father is the perpetrator although it was not possible to judge precisely as the case files did not contain any recorded data on the time of parental divorce. The higher percentage of incest victims living in institution care also seems to be associated with the fact that the child is placed in an institution for the purpose of the child's protection following the disclosure of incest. Although the current study is not a population-based investigation aiming to identify the risk factors, sociodemographic differences detected among the groups are remarkable.
School is a structured and protected environment enabling children to establish relationships of social support with their peers. Meinck et $\mathrm{al}^{26}$ demonstrated that dropping out from school posed a risk of sexual abuse in the follow-up. The current study, too, found out that approximately half of the female adolescents did not continue schooling. The percentage of the girls who had dropped out before the abuse was not different from the mean urban percentage issued by the Turkish Statistical Institute (19.3\%). ${ }^{27}$ The rate of dropping out after the abuse, on the other hand, was quite high, and it was particularly significant in sexual dating violence cases. Postabuse psychiatric symptoms and functional impairment may be a cause of dropping out in the high percentage of victims. Another possible cause may be the family forcing the girl into dropping out due to their concern over revictimization particularly in sexual dating violence cases. It was, on the other hand, shown in a study of women with CSA histories that a higher level of education was associated with lower levels of distress and argued that education was an important personal resource to cope with traumatic experiences. ${ }^{28}$ It appears that ensuring the continuance of schooling for female adolescents would be of importance with regard to improving their skills in both protection from abuse and coping with the aftermath of the abuse.

In this study, we found that characteristics of the abusive act also differed among the groups. Incest victims were the cases who were abused at the youngest ages. Sexual dating violence, on the other hand, was found to have happened at an older age when compared with the other types of abuse. It is argued that the likelihood of entering into a relationship that involves violence is increased as the number of dating partners increase, resulting in a higher prevalence of dating violence in adolescents at older ages. ${ }^{11}$ It is known that chronic abuse and delays in reporting abuse are common in incest cases. ${ }^{29}$ It was found in the current study, too, that the percentage of exposure to chronic abuse by the same perpetrator was the highest and the time elapsing from the first abusive episode until its reporting was the longest in incest victims. Physical assault rate was higher both in incest and in sexual dating violence victims than in other CSA victims. The rates of having been abused by more than one perpetrator, revictimization, penetrative abuse and threats, on the other hand, were higher in the sexual dating violence group. These findings suggest that the incest and particularly sexual dating violence victims are subjected to more severe abuse when compared with cases who suffered abuse by other perpetrators. 
A systematic review and meta-analysis research found that sexual abuse history in childhood was associated with lifetime diagnosis of anxiety disorder, depression, eating disorders, PTSD, sleep disorders, and attempted suicide. ${ }^{15}$ The percentage of psychiatric disorders reported in studies of CSA cases in Turkey, which were referred to child and adolescent psychiatry clinics by penal authorities for forensic evaluation in a similar way to the current study, is in the range of $55.0 \%-87.9 \%{ }^{30-33}$ More severe forms of sexual abuse are reported to authorities more frequently. ${ }^{20}$ The high percentages of psychiatric disorders observed in the cases that were subjected to forensic evaluation are, therefore, not a surprising result. The percentage of psychiatric disorders found in the current study was, on the other hand, even higher than the figures in the aforementioned studies. This consequence may have resulted from the inclusion of only female adolescents in the current study. It was noted that being a female in sexual abuse cases increases the risk of psychiatric disorders twofold and that the prevalence of psychiatric disorders increases with age. ${ }^{29}$ Consistent with the literature, we found that major depressive disorder and PTSD were the most common post-abuse psychiatric disorders. ${ }^{30-35} \mathrm{We}$ determined that both the rate of any psychiatric disorder and the rate of depression were higher in the sexual dating violence group. This consequence may be associated with the fact that the adolescents who fall victim to sexual dating violence are subjected to a higher extent to more severe forms of abuse such as penetration, threats, and revictimization.

Suicidality and NSSI are matters of great concern for mental health professionals who deal with adolescents. Systematic reviews of population-based epidemiological studies found that $9.7 \%$ of adolescents attempted suicide and $29.9 \%$ had suicidal ideation at least once in their life ${ }^{36}$ and that the lifetime NSSI prevalence was $18.0 \% .{ }^{37}$ Previous studies have demonstrated that a history of sexual abuse is a significant risk factor for attempted suicide and suicidal ideation. ${ }^{38-40}$ Nevertheless, a meta-analysis showed that there was a relatively lesser association between CSA and NSSI, and that such association resulted from the fact that both the conditions involved common risk factors ${ }^{41}$ The current study found that history of attempted suicide in $25.6 \%$ of the cases, suicidal ideation in $52.0 \%$ of the cases, history of NSSI in $23.6 \%$ of the cases, and the rates of attempted suicide and suicidal ideation, in particular, were markedly higher than those estimated in population-based studies.

Earlier studies suggested that psychopathology may partially mediate the association between CSA and suicidality. ${ }^{42}$
The current study found that the presence of depression increased the odds for attempted suicide and suicidal ideation by more than twofold and threefold, respectively, and that alcohol/substance use disorders, on the other hand, were associated with NSSI. Postabuse suicidality appeared to be associated with the perpetrator identity and revictimization as well as the resulting psychiatric disorder. Dating violence victimization was the strongest predictor for both attempted suicide and suicidal ideation, even after controlling for psychiatric disorders. On the other hand, there was no significant relationship between incest and suicidality. The lack of significant results in the current study could be due to the limited sample size in the incest group. Our results are consistent with the hypothesis that negative effects of abuse are associated not only with the objective characteristics of the abusive act but also with the subjective perception. ${ }^{28}$ Social stigmatization of the victim is an important problem in Turkish culture, ${ }^{43}$ which may be contributing to the negative effects of sexual dating violence. The increased risk of suicidality in the sexual dating violence group that we detected may be associated with the poor social support as well as selfblame. It was found in previous studies that being in a close relationship with the perpetrator and having suffered from long-lasting and more severe sexual abuse were associated with an increased level of self-blame. ${ }^{44}$ It was reported that the level of self-blame resulting from the abuse was lower in incest cases, which was arguably associated with strong and consistent messages given to victims about the abuse was not their fault. ${ }^{45}$ In sexual dating violence, on the other hand, the perpetrator is somebody with whom the victim is in a romantic relationship. Being a victim of sexual violence in the context of a flirtatious relationship in a traditionalistic society where such relationships are not favored may be leading to being condemned by both the family and the community as well as blaming the self rather than the perpetrator.

Previous studies revealed that more invasive and multiple sexual abuse experiences have more negative effects and are associated with more psychopathology. ${ }^{28,46}$ Chronic abuse is identified as an important factor that increases the risk of suicidality. ${ }^{31}$ The current study did not yield any association of chronic abuse victimization by the same perpetrator with suicidality and NSSI, although revictimization was found to be associated with both suicidal ideation and NSSI. Revictimized victims are reported to be prone to a higher risk of developing psychopathology, ${ }^{47}$ and it is stated that being abused by multiple perpetrators is associated with increased vulnerability not only in adolescence but also in adulthood. ${ }^{48}$ Follow-up and treatment of revictimized adolescents, 
therefore, appear to be of importance with respect to minimization of both short-term and long-term negative effects.

While the current study offers certain results to identify sexually victimized adolescents at risk of suicidality and NSSI, a number of limitations need to be mentioned. The study's retrospective chart review design is an important limitation. The fact, on the other hand, that all the data were collected via a standard data form has significantly reduced the percentage of missing data. Sexual abuse, under the Turkish Penal Code, ${ }^{16}$ is among those cases where the health care professional is required to complete forensic reporting. Conducting population-based studies on sexual abuse in childhood and adolescence in Turkey is, therefore, difficult as it may lead to legal and ethical issues. There was no male case referred on grounds of sexual dating violence during the time frame of the study, only the data of female adolescents are included in the study. It should, therefore, be taken into consideration that the results cannot be generalized across male victims of CSA and other age groups. Furthermore, as only the cases with forensic reporting were included in the current study, it is difficult to generalize results across the general population. Other biological, psychological, or social factors not captured in the current study may also be important for suicidality and NSSI in sexually victimized female adolescents and should be considered in future research. Further work is needed to examine the cultural differences in the development of suicidality and NSSI in sexually abused adolescents.

Despite these limitations, this study has important implications for health care professionals. Although the literature contains numerous studies on the negative effects of sexual abuse, the current study, to the best of our knowledge, is the first one to have compared the sexual dating violence victims with incest and other CSA cases. The present study reveals that being a victim of dating violence is associated with higher odds of attempted suicide and suicidal ideation. An awareness of the association between different abuse types and suicidality can lead to the design of effective preventive strategies.

\section{Conclusion}

Our results revealed that approximately one-quarter of the sexually victimized female adolescents had attempted suicide, that another quarter exhibited self-injurious behaviors, and that approximately half of them had suicidal ideation. Such high rates point to the vitality of identifying the adolescents at higher risk, in particular, and of planning more intensified efforts to address them. Intervention programs aiming to prevent the exposure of children and adolescents to sexual abuse and sexual dating violence (such as schoolbased prevention programs and parental education schemes) are of primary importance. The odds for suicidality should be borne in mind while tackling the sexual dating violence cases particularly in more traditionalistic societies as ours. Revictimization is encountered as a factor associated with negative mental health outcomes. Ensuring protection of the victims of abuse from revictimization through appropriate methods of tertiary prevention may play a key role in minimizing the risk of suicidality and NSSI.

\section{Acknowledgments}

The authors received no funding for this study. We wish to thank Mrs FN Langdon for language editing.

\section{Disclosure}

The authors report no conflicts of interest in this work.

\section{References}

1. The International Society for the Prevention of Child Abuse and Neglect (ISPCAN) [webpage on the Internet]. ISPCAN 'Denver thinking space' 2011: child sexual abuse. Available from: http://c.ymcdn.com/sites/www. ispcan.org/resource/resmgr/events/ispcan_denver_thinking_space.pdf. Accessed March 31, 2016.

2. Barth J, Bermetz L, Heim E, Trelle S, Tonia T. The current prevalence of child sexual abuse worldwide: a systematic review and meta-analysis. Int J Public Health. 2013;58(3):469-483.

3. Spataro J, Moss SA, Wells DL. Child sexual abuse: a reality for both sexes. Aust Psychol. 2001;36(3):177-183.

4. Stoltenborgh M, van IJzendoorn MH, Euser EM, BakermansKranenburg MJ. A global perspective on child sexual abuse: meta-analysis of prevalence around the world. Child Maltreat. 2011;16(2):79-101.

5. Zoroglu SS, Tuzun U, Sar V, Ozturk O, Kara ME, Alyanak B. Çocukluk dönemi istismar ve ihmalinin olası sonuçları [Probable results of childhood abuse and neglect]. Anadolu Psikiyatri Derg. 2001;2(2):69-78. [Turkish].

6. Eskin M, Kaynak-Demir H, Demir S. Same-sex sexual orientation, childhood sexual abuse, and suicidal behavior in university students in Turkey. Arch Sex Behav. 2005;34(2):185-195.

7. Alikasifoglu M, Erginoz E, Ercan O, Albayrak-Kaymak D, Uysal O, Ilter O. Sexual abuse among female high school students in Istanbul, Turkey. Child Abuse Negl. 2006;30(3):247-255.

8. Mulford CF, Blachman-Demner DR. Teen dating violence: building a research program through collaborative insights. Violence Against Women. 2013;19(6):756-770.

9. Rizzo CJ, Esposito-Smythers C, Swenson L, Hower HM, Wolff J, Spirito A. Dating violence victimization, dispositional aggression, and nonsuicidal self-injury among psychiatrically hospitalized male and female adolescents. Suicide Life Threat Behav. 2014;44(3):338-351.

10. Silverman JG, Raj A, Mucci LA, Hathaway JE. Dating violence against adolescent girls and associated substance use, unhealthy weight control, sexual risk behavior, pregnancy, and suicidality. JAMA. 2001;286(5):572-579.

11. Rizzo CJ, Esposito-Smythers C, Spirito A, Thompson A. Psychiatric and cognitive functioning in adolescent inpatients with histories of dating violence victimization. $J$ Aggress Maltreat Trauma. 2010;19(5):565-583.

12. Wolitzky-Taylor KB, Ruggiero KJ, Danielson CK, et al. Prevalence and correlates of dating violence in a national sample of adolescents. J Am Acad Child Adolesc Psychiatry. 2008;47(7):755-762. 
13. Chen LP, Murad MH, Paras ML, et al. Sexual abuse and lifetime diagnosis of psychiatric disorders: systematic review and meta-analysis. Mayo Clin Proc. 2010;85(7):618-629.

14. Kanamüller J, Riala K, Nivala M, Hakko H, Räsänen P. Correlates of sexual abuse in a sample of adolescent girls admitted to psychiatric inpatient care. J Child Sex Abus. 2014;23(7):804-823.

15. Jonas $\mathrm{S}$, Bebbington $\mathrm{P}, \mathrm{McManus} \mathrm{S}$, et al. Sexual abuse and psychiatric disorder in England: results from the 2007 Adult Psychiatric Morbidity Survey. Psychol Med. 2011;41(4):709-719.

16. Turkish Penal Code. Law no: 5237. Official Gazette; 2004. Available from: http://www.mevzuat.gov.tr/MevzuatMetin/1.5.5237.pdf. Accessed March 31, 2016.

17. American Psychiatric Association. Diagnostic and Statistical Manual of Mental Disorders, 4th ed, Text Revision (DSM-IV-TR). Washington, DC: American Psychiatric Association; 2000.

18. Bernet W. Child maltreatment. In: Sadock BJ, Sadock VA, editors. Kaplan and Sadock's Comprehensive Textbook of Psychiatry. 7th ed. Philadelphia: Lippincott Williams and Wilkins; 2000:2878-2889.

19. Garcia-Moreno C, Jansen H, Ellsberg M, Heise L, Watts C. WHO Multi-Country Study on Women's Health and Domestic Violence Against Women. Geneva: World Health Organization; 2005.

20. Maier T, Mohler-Kuo M, Landolt MA, Schnyder U, Jud A. The tip of the iceberg. Incidence of disclosed cases of child sexual abuse in Switzerland: results from a nationwide agency survey. Int J Public Health. 2013;58(6):875-883.

21. Kogan SM. Disclosing unwanted sexual experiences: results from a national sample of adolescent women. Child Abuse Negl. 2004;28(2): 147-165.

22. Murray LK, Nguyen A, Cohen JA. Child sexual abuse. Child Adolesc Psychiatr Clin N Am. 2014;23(2):321-337.

23. Yildirim A, Ozer E, Bozkurt H, et al. Evaluation of social and demographic characteristics of incest cases in a university hospital in Turkey. Med Sci Monit. 2014;20:693-697.

24. Gencer O, Ozbek A, Ozyurt G, Kavurma C. Çocuk ve ergenlerde aile dışı ve aile içi cinsel istismar olgularının karşılaştırılması [A comparison of extra and intra-familial sexual abuse of children and adolescents]. Anadolu Psikiyatri Derg. 2016;17(1):56-64. [Turkish].

25. Chan KL, Yan E, Brownridge DA, Ip P. Associating child sexual abuse with child victimization in China. J Pediatr. 2013;162(5):1028-1034.

26. Meinck F, Cluver LD, Boyes ME. Longitudinal predictors of child sexual abuse in a large community-based sample of South African youth. J Interpers Violence. 2015. pii: 0886260515596331.

27. Turkish Statistical Institute [webpage on the Internet]. Denizli with selected indicators; 2013. Available from: http://www.tuik.gov.tr/ ilGostergeleri/iller/DENIZLI.pdf. Accessed March 31, 2016.

28. Lev-Wiesel R, Markus L. Perception vs. circumstances of the child sexual abuse event in relation to depression and post-traumatic stress symptomatology. J Child Sex Abus. 2013;22(5):519-533.

29. Aydin B, Akbas S, Turla A, Dundar C, Yuce M, Karabekiroglu K. Child sexual abuse in Turkey: an analysis of 1002 cases. J Forensic Sci. 2015; 60(1):61-65.

30. Ozbaran B, Erermis S, Bukusoglu N, et al. Social and emotional outcomes of child sexual abuse: a clinical sample in Turkey. $J$ Interpers Violence. 2009;24(9):1478-1493.
31. Soylu N, Alpaslan AH. Suicidal behavior and associated factors in sexually abused adolescents. Child Youth Serv Rev. 2013;35(2): $253-257$.

32. Soylu N, Ayaz M, Yuksel T. Early-married and sexually abused girls differ in their psychiatric outcomes. Child Abuse Negl. 2014;38(9): 1552-1559.

33. Imren SG, Ayaz AB, Yusufoglu C, Arman AR. Cinsel istismara uğrayan çocuk ve ergenlerde klinik özellikler ve intihar girişimi ile ilişkili risk etmenleri [Clinical features and risk factors related with suicide attempts in sexually abused children and adolescents]. Marmara Med J. 2013;26:11-16. [Turkish].

34. Brabant ME, Hébert M, Chagnon F. Identification of sexually abused female adolescents at risk for suicidal ideations: a classification and regression tree analysis. J Child Sex Abus. 2013;22(2):153-172.

35. Putnam FW. Ten-year research update review: child sexual abuse. J Am Acad Child Adolesc Psychiatry. 2003;42(3):269-278.

36. Evans E, Hawton K, Rodham K, Deeks J. The prevalence of suicidal phenomena in adolescents: a systematic review of population-based studies. Suicide Life Threat Behav. 2005;35(3):239-250.

37. Muehlenkamp JJ, Claes L, Havertape L, Plener PL. International prevalence of adolescent non-suicidal self-injury and deliberate self-harm. Child Adolesc Psychiatry Ment Health. 2012;6:10.

38. Akyuz G, Sar V, Kugu N, Dogan O. Reported childhood trauma, attempted suicide and self-mutilative behavior among women in the general population. Eur Psychiatry. 2005;20(3):268-273.

39. Maniglio R. The role of child sexual abuse in the etiology of suicide and non-suicidal self-injury. Acta Psychiatr Scand. 2011;124(1):30-41.

40. Miller AB, Esposito-Smythers C, Weismoore JT, Renshaw KD. The relation between child maltreatment and adolescent suicidal behavior: a systematic review and critical examination of the literature. Clin Child Fam Psychol Rev. 2013;16(2):146-172.

41. Klonsky ED, Moyer A. Childhood sexual abuse and non-suicidal selfinjury: meta-analysis. Br J Psychiatry. 2008;192(3):166-170.

42. Bedi S, Nelson EC, Lynskey MT, et al. Risk for suicidal thoughts and behavior after childhood sexual abuse in women and men. Suicide Life Threat Behav. 2011;41(4):406-415.

43. Sahin F, Cepik-Kuruoglu A, Demirel B, et al. Six-year experience of a hospital-based child protection team in Turkey. Turk J Pediatr. 2009;51(4):336-343.

44. Quas JA, Goodman GS, Jones D. Predictors of attributions of self-blame and internalizing behavior problems in sexually abused children. JChild Psychol Psychiatry. 2003;44(5):723-736.

45. Feiring $\mathrm{C}$, Cleland $\mathrm{C}$. Childhood sexual abuse and abuse-specific attributions of blame over 6 years following discovery. Child Abuse Negl. 2007;31(11-12):1169-1186.

46. Leserman J. Sexual abuse history: prevalence, health effects, mediators, and psychological treatment. Psychosom Med. 2005;67(6):906-915.

47. Kaltman S, Krupnick J, Stockton P, Hooper L, Green BL. Psychological impact of types of sexual trauma among college women. J Trauma Stress. 2005;18(5):547-555.

48. Lau M, Kristensen E. Sexual revictimization in a clinical sample of women reporting childhood sexual abuse. Nord J Psychiatry. 2010;64(1): 4-10.
Neuropsychiatric Disease and Treatment

\section{Publish your work in this journal}

Neuropsychiatric Disease and Treatment is an international, peerreviewed journal of clinical therapeutics and pharmacology focusing on concise rapid reporting of clinical or pre-clinical studies on a range of neuropsychiatric and neurological disorders. This journal is indexed on PubMed Central, the 'PsycINFO' database and CAS,

\section{Dovepress}

and is the official journal of The International Neuropsychiatric Association (INA). The manuscript management system is completely online and includes a very quick and fair peer-review system, which is all easy to use. Visit http://www.dovepress.com/testimonials.php to read real quotes from published authors. 